\title{
Ethological analysis of mother-pup interactions and other behavioral reactions in rats: effects of malnutrition and tactile stimulation of the pups
}

\section{T.R. Riul, A.F. Carvalho, P.S. Almeida, L.M. De-O liveira and S.S. Almeida}

\author{
Laboratório de Nutrição e Comportamento, Faculdade de Filosofia, \\ Ciências e Letras de Ribeirão Preto, U niversidade de São Paulo, \\ Ribeirão Preto, SP, Brasil
}

\section{Correspondence \\ S.S. Almeida \\ Laboratório de Nutrição e \\ Comportamento, FFCLRP, USP \\ Av. dos Bandeirantes, 3900 \\ 14040-901 Ribeirão Preto, SP \\ Brasil \\ Fax: + 55-16-633-5015 \\ E-mail: sebasalm@usp.br}

Research supported by FAPESP (No. 95/9501-2), and CNPq (Nos. 523325/95-9 and 500833/90-7) to S.S. Almeida and L.M. De-O liveira. S.S. Almeida and L.M. De-O liveira were recipients of $\mathrm{CNPq}$ fellowships. P.S. Almeida and A.F. Carvalho were recipients of CNPq scholarships.

Received June 5, 1998 Accepted March 18, 1999

\section{Abstract}

Mother-pup interaction, as well as other behavioral reactions were studied during the lactation period in 24 litters of Wistar rats and their dams fed either a $16 \%$ (control - C; 12 litters) or a $6 \%$ (malnourished - M; 12 litters) protein diet. The diets were isocaloric. Throughout lactation there was a $36.4 \%$ weight loss of $\mathrm{M}$ dams and a $63 \%$ body weight deficit in the $\mathrm{M}$ pups when compared to control pups. During this period, half of the litters were exposed daily to additional tactile stimulation (CS or MS), while the other half were submitted to normal rearing conditions $(\mathrm{CN}$ or $\mathrm{MN})$. The tactile stimulation of pups (handling) consisted of holding the animal in one hand and gently touching the dorsal part of the animal's body with the fingers for 3 min. A special camera and a time-lapse video were used to record litter behavior in their home cages. Starting at 6 p.m. and ending at 6 a.m., on days $3,6,12,15,18$ and 21 of lactation, photos were taken at 4-s intervals. An increase in the frequency $(154.88 \pm 16.19)$ and duration $(455.86 \pm 18.05 \mathrm{~min})$ of suckling was observed throughout the lactation period in all groups compared to birth day (frequency $24.88 \pm 2.37$ and duration $376.76 \pm 21.01 \mathrm{~min}$ ), but the frequency was higher in the $\mathrm{C}(84.96 \pm 8.52)$ than in the $\mathrm{M}$ group $(43.13 \pm 4.37)$; however, the $\mathrm{M}$ group (470.2 $\pm 11.87 \mathrm{~min}$ ) spent more time suckling as compared with the $\mathrm{C}$ group $(393.67 \pm 13.09 \mathrm{~min})$. The $\mathrm{M}$ dams showed a decreased frequency of resting position throughout the lactation period $(6.5 \pm$ $2.48)$ compared to birth day $(25.42 \pm 7.74)$. Pups from the $C$ group were more frequently observed separated $(73.02 \pm 4.38)$ and interacting $(258.99 \pm 20.61)$ more with their mothers than the $M$ pups (separated $66.94 \pm 5.5$ and interacting $165.72 \pm 12.05$ ). Tactile stimulation did not interact with diet condition, showing that the kind of stimulation used in the present study did not lead to recovery from the changes induced by protein malnutrition. The changes in mother-pup interaction produced by protein malnutrition of both may represent retardation in neuromotor development and a higher dependence of the pups on their mothers. These changes may represent an important means of energy saving and heat maintenance in malnourished pups.
Key words

- Protein malnutrition

- Tactile stimulation

- Mother-pup interaction 


\section{Introduction}

Early protein malnutrition and environmental stimulation lead to morphological and neurochemical changes in the central nervous system (CNS), as well as to longterm consequences in terms of behavioral expression (1-4). The effects of environmental enrichment on the CNS have been described elsewhere in detail (4). Rats exposed to environmental stimulation early in life, such as handling, showed lower emotionality and higher exploration in a new environment (1). The environmental stimulation resulted in changes in the reaction to a new environment, increasing the exploration of the open arms of the elevated plusmaze and the exploration of the light side of the light-dark box (5), in well-nourished and previously malnourished adult animals, even in the absence of a main effect of the protein deficient diet.

The behavioral consequences of early malnutrition are not due only to the lack of nutrients, but are enhanced by the lack of or reduced environmental stimulation in malnourished populations (6). There is clear evidence that early environmental stimulation reduces or modifies the behavioral effects of malnutrition. Levitsky and Barnes (7), analyzing the combined effects of early protein malnutrition, environmental stimulation and isolation on the behavior of adult rats, showed that malnutrition increased the locomotor activity and decreased both the exploration of a new environment and social interactions when the animals were raised under standard laboratory conditions. An enhancement of this effect was observed when the animals were raised in an environment with low stimulation (isolation). In contrast, opposite effects were observed when the animals received additional environmental stimulation. The malnourished animals raised in an enriched environment showed locomotion and exploration in a new environment similar to those of the control animals.
Early protein malnutrition changes the behavior of mother and pups as well as mother-pup interactions during the lactation period. Massaro et al. (8) showed that malnourished mothers spent more time in the nest area with enhanced maternal behavior in contrast to the control mothers that were more frequently observed in non-maternal behavior such as grooming, rearing and lying down in a horizontal position outside the nesting area. Similar results were reported for rats by Levitsky et al. (9) and De Oliveira (10). The description of similar behavioral patterns in children from rural areas in Mexico (11) emphasizes the importance of environmental isolation (12) to understand the behavioral consequences of early malnutrition.

Most studies in the literature describe the long-term consequences of early malnutrition, showing brain and behavioral changes in adult life. Even though the early experiences, especially in the first weeks of life, are important determinants of adult behavior, there are few reported data describing systematic changes in malnourished animals during exposure to a low protein diet. Thus, the objective of the present study was to investigate the effects of early protein malnutrition and tactile stimulation on the behavior of the mothers and pups, as well as mother-pup interactions during the lactation period. An experimental protocol designed to take a picture of the litters every 4 s throughout the dark period (6 p.m. to 6 a.m.) was used. This protocol represents a great advance when compared to a previous study reported in the literature (8) where one picture was taken every $3 \mathrm{~min}$, because the present procedure permits a better analysis of the frequency and duration of behavioral patterns during lactation.

\section{Material and Methods}

\section{Subjects}

Female virgin Wistar rats aged approxi- 
mately 90 days were mated in our laboratory. Within $24 \mathrm{~h}$ after parturition, litters of 8 pups (6 males and 2 females) were formed at random from a larger pool of pups. The mother and litters were maintained in a special lactation cage $(40 \times 30 \times 20 \mathrm{~cm})$ with three sides of transparent Plexiglas allowing observation and filming during the lactation period. The litters were randomly assigned to isocaloric diets containing 16\% (control - C) or $6 \%$ protein (malnourished - M). The diets were prepared according to Santucci et al. (5) and Rocinholi et al. (13) and were offered ad libitum to the litters from birth to 22 days of age. Half of the pups in each litter were exposed daily to an additional 3 min of stimulation (CS or MS). The tactile stimulation (handling) consisted of holding the animal in one hand and gently touching the dorsal part of the animal's body with the fingers. The other half of the pups were submitted to normal rearing conditions without additional stimulation ( $\mathrm{CN}$ or $\mathrm{MN}$ ). Since the stimulation of all litters took approximately $24 \mathrm{~min}$, the non-stimulated pups were separated from their mother for an equivalent period of time. Environmental stimulation was performed from birth to weaning (22nd day). The animals were weighed on days 1,7 , 14 and 21 of lactation, when the nesting material was changed.

\section{Apparatus}

A highly sensitive camera (Toshiba, model IK-536A) and a time-lapse video (Panasonic, model AG-6040), a black and white monitor (Panasonic, model WV-5410) and a time-date generator (Panasonic, model WJ-810) were used to record mother and pup behavior. The camera was fixed on the wall at a distance of $270 \mathrm{~cm}$ from the cage. Two cages were filmed simultaneously. A red light bulb $(15 \mathrm{~W})$ provided sufficient illumination.

\section{Procedure}

The litters were filmed on days $3,6,12$,
15,18 and 21 of lactation, with frames every 4-s during the dark phase of the 12-h lightdark cycle, starting at 6 p.m. Six litters per treatment were used. The tapes were analyzed using a behavioral protocol similar to that described by Massaro et al. (8), and the following categories were analyzed by two independent observers:

Suckling. Regardless of mother's behavior, at least one pup was observed suckling. The frequency and duration of this category were analyzed.

Visit to the feeding tunnel. The mother was observed with her nose in the food tunnel. With this technique it was not possible to record the intake or ingestive behavior. The frequency and duration of this category were analyzed.

Mother-pup interaction. Active motherpup interaction. When at least one pup was observed licking, sniffing or climbing over the mother or the mother was observed in an active interaction with the pups such as licking, sniffing or transporting the pups from one place to another in the cage. The frequency and duration of this category were analyzed.

Separated litters. When the pups were observed separated into two or more groups. Only the frequency of this category was analyzed.

Resting position. When the mother was observed lying down on the floor of the cage, in a horizontal position, without contact with the pups. Only the frequency was analyzed.

\section{Statistical analysis}

Mother and pup body weights, as well as behavioral data were studied by a threefactor (diet, tactile stimulation and days) analysis of variance (ANOVA), with repeated measures in the last factor (days). The posthoc analysis was conducted using the Newman-Keuls test. The Statistica ${ }^{\odot}$ statistical package was used, with the level of significance set at $\mathrm{P}<0.05$. 


\section{Results}

Starting with similar body weights $(290.91 \pm 3.86 \mathrm{~g})$, dams of both nutritional groups lost weight throughout the lactation period as shown by a significant effect of days $(\mathrm{F}(3,87)=119.58, \mathrm{P}<0.001)$. However, a greater decrease in the body weight of malnourished dams as compared to control dams showed a significant effect of diet $(\mathrm{F}(1,20)=204.83, \mathrm{P}<0.001)$, as well as a significant effect of diet by day interaction $(\mathrm{F}(3,87)=55.49, \mathrm{P}<0.001)$. By the end of the lactation period, a $36.4 \%$ body weight loss was observed in malnourished dams as compared with only $3.1 \%$ in the control group. A lower decrease in the body weight of dams whose pups were not stimulated $(18.7 \%)$ as compared with dams whose pups were stimulated (24.9\%) throughout the lactation period produced a significant effect of tactile stimulation by day interaction $(\mathrm{F}(3,87)$ $=3.55, \mathrm{P}<0.01)$. No effects of stimulation, diet by stimulation interaction or diet by stimulation by day interaction were observed.

Despite similar pup birth weights $(6.48 \pm$ $0.11 \mathrm{~g}$ for controls and $6.54 \pm 0.09 \mathrm{~g}$ for

Figure 1 - Frequency (A and $B$ ) and duration (C) of suckling behavior on each lactation day during the night period $(6$ p.m. to 6 a.m.). Each bar represents the mean \pm SEM. Control $(C)=C N$ $+\mathrm{CS}(\mathrm{N}=12$ litters); malnourished $(\mathrm{M})=\mathrm{MN}+\mathrm{MS}(\mathrm{N}=12$ litters); non-stimulated $(\mathrm{N})=\mathrm{CN}$ $+\mathrm{MN}(\mathrm{N}=12$ litters); stimulated $(\mathrm{S})=\mathrm{CS}+\mathrm{MS}(\mathrm{N}=12$ litters $)$. $* \mathrm{P}<0.05$ compared to malnourished (A) and control (C) animals, and $* \mathrm{P}<0.05$ compared to stimulated animals (B).

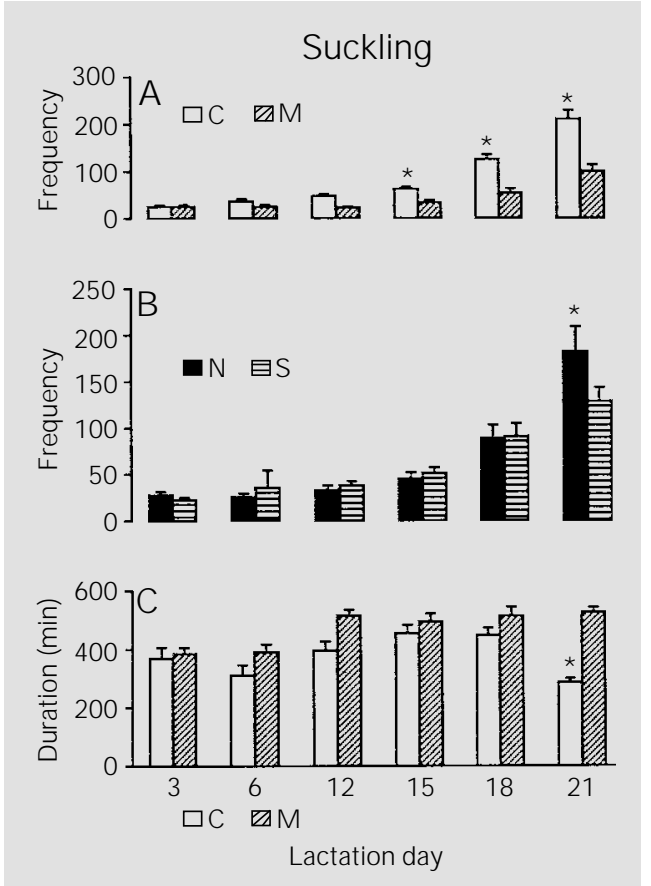

malnourished), the control group showed a higher increase $(\mathrm{F}(1,19)=353.96, \mathrm{P}<0.001)$ in body weight than the malnourished group throughout the lactation period. Although the body weight of both nutritional groups increased during lactation $(\mathrm{F}(3,87)=994.66$, $\mathrm{P}<0.001)$, the lower increase in the malnourished group showed a significant diet by day interaction $(F(3,87)=372.10, P<0.001)$. By the end of the lactation period the mean body weight of the controls was $40.76 \pm 1.13 \mathrm{~g}$ as compared with $15.03 \pm 0.38 \mathrm{~g}$ for the malnourished animals. No effects of tactile stimulation were observed.

\section{Suckling}

As illustrated in Figure 1A, ANOVA indicated an increase in the frequency of suckling throughout the lactation period for both nutritional groups as shown by a significant overall effect of days $(F(5,100)=103.63$, $\mathrm{P}<0.001$ ), a higher frequency of suckling in control animals as shown by a significant overall effect of diet $(F(1,20)=41.74$, $\mathrm{P}<0.001$ ), as well as a greater increase in the frequency of suckling in control animals as compared to malnourished ones throughout the lactation period, as indicated by a significant diet by day interaction $(\mathrm{F}(5,100)=17.80$, $\mathrm{P}<0.001)$. Post-hoc analysis showed higher frequencies of suckling in control animals on days 15,18 , and 21 of the lactation period $(\mathrm{P}<0.05)$. In addition, as illustrated in Figure $1 \mathrm{~B}$, a greater increase $(\mathrm{P}<0.05)$ in the frequency of suckling in non-stimulated animals on the 21 st day of lactation, as compared with stimulated animals, produced a significant interaction between tactile stimulation and days $(\mathrm{F}(5,100)=6.01, \mathrm{P}<0.001)$. No effects of stimulation, diet by stimulation interaction or diet by stimulation by day interaction were observed.

Although malnourished animals showed a lower frequency of suckling during the lactation period, their duration of suckling was greater compared to controls (Figure 
1C), as evidenced by a significant effect of $\operatorname{diet}(\mathrm{F}(1,20)=12.96, \mathrm{P}<0.001)$. In addition, the duration of suckling increased throughout the lactation period for both groups, as shown by a significant effect of days $(F(5,100)=9.73, P<0.001)$. No effects of stimulation, or of any interaction among the factors studied was observed.

\section{Visits to the feeding tunnel}

The frequency of visits to the feeding tunnel was not affected by any of the variables studied. However, the duration of the visits increased throughout the lactation period (Figure 2A) for both nutritional groups $(\mathrm{F}(5,100)=6.56, \mathrm{P}<0.001)$. Post-hoc analyses showed that animals spent more time in the feeding tunnel on days 18 and 21 of lactation as compared with all other days $(\mathrm{P}<0.05)$. No other variables studied affected the duration of visits to the feeding tunnel.

\section{Mother in the resting position}

As illustrated in Figure 2B, ANOVA showed a lower frequency of malnourished mothers in the resting position when compared with control mothers, as indicated by a significant overall effect of diet $(\mathrm{F}(1,20)=$ $33.04, \mathrm{P}<0.001)$. The frequency of mothers in the resting position decreased throughout the lactation period as indicated by a significant overall effect of days $(F(5,100)=6.04$, $\mathrm{P}<0.001)$; however, this decrease was evident only for malnourished mothers, showing a significant effect of diet by day interaction $(\mathrm{F}(5,100)=2.96, \mathrm{P}<0.05)$. Post-hoc analyses showed a lower frequency of resting position in malnourished mothers as compared with control ones on days $6,12,15,18$ and 21 of the lactation period. A significant effect of tactile stimulation by day interaction was also found $(F(5,100)=4.61$, $\mathrm{P}<0.001$ ), indicating that non-stimulated animals maintained a similar frequency of resting position throughout the lactation period while stimulated animals increased this frequency from day 3 to day 6 and decreased it again on the remaining days (Figure 2C). Post-hoc analysis showed a higher frequency of stimulated mothers in the resting position as compared with non-stimulated mothers on day 6 of lactation $(\mathrm{P}<0.05)$. No effects of stimulation, diet by stimulation interaction or diet by stimulation by day interaction were observed.

\section{Separated litters}

As illustrated in Figure 3A, there was an increase in the frequency of separated litters throughout the lactation period for both nutritional groups, as indicated by an overall effect of days $(\mathrm{F}(3,60)=17.23, \mathrm{P}<0.001)$. However, this increase was higher for control animals from day 12 to day 18 and the

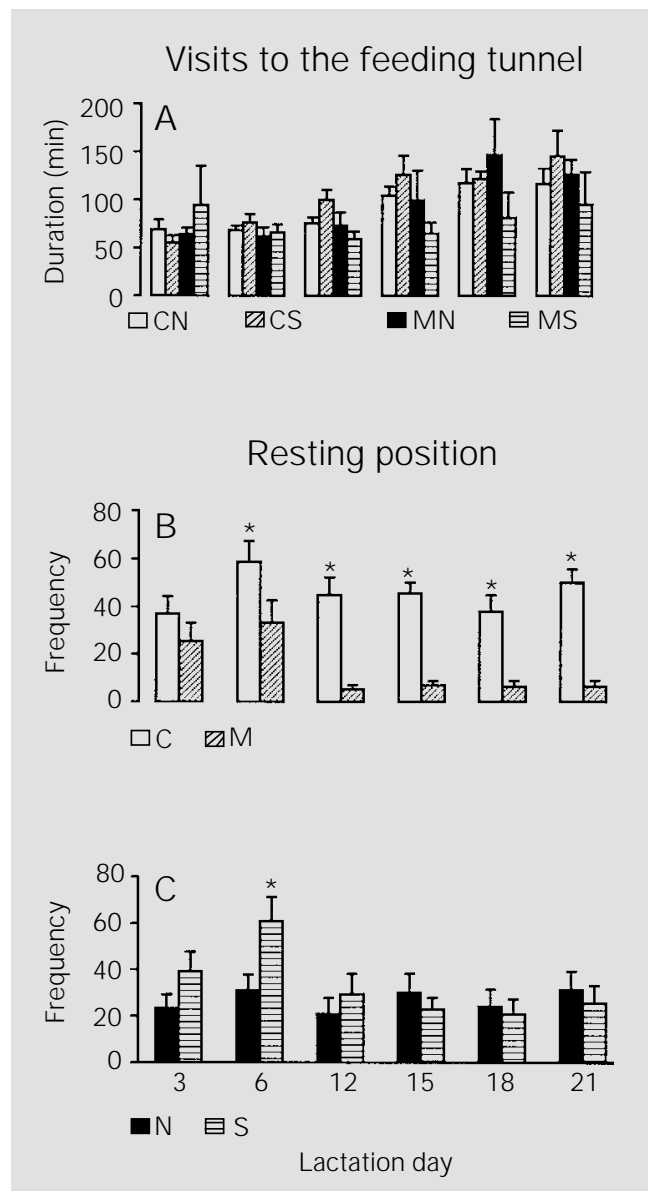

Figure 2 - Duration of the visits to the food tunnel $(A)$ and mean frequency of the mother in a resting position without contact with the pups ( $B$ and $C$, respectively) throughout the lactation period. Each bar represents the mean \pm SEM during the night period (6 p.m. to 6 a.m.). $\mathrm{CN}=$ Control non-stimulated $(\mathrm{N}=6$ litters); $\mathrm{CS}=$ control stimulated $(\mathrm{N}=6$ litters); $\mathrm{MN}=$ malnourished non-stimulated ( $\mathrm{N}=6$ litters); $\mathrm{MS}=$ malnourished stimulated ( $\mathrm{N}=6$ litters). $\mathrm{C}=\mathrm{CN}+\mathrm{CS}$ ( $\mathrm{N}=12$ litters); $\mathrm{M}=\mathrm{MN}+\mathrm{MS}$ ( $\mathrm{N}$ $=12$ litters); $\mathrm{N}=\mathrm{CN}+\mathrm{MN}(\mathrm{N}=$ 12 litters); $\mathrm{S}=\mathrm{CS}+\mathrm{MS}$ ( $\mathrm{N}=12$ litters). $* \mathrm{P}<0.05$ compared to malnourished animals (B) and *P $<0.05$ compared to non-stimulated animals (C). 
opposite (i.e., lower for control animals) observed on day 21 of lactation $(\mathrm{P}<0.05)$, showing a significant effect of diet by day interaction $(\mathrm{F}(3,60)=15.45, \mathrm{P}<0.001)$.

\section{Mother-pup interaction}

As illustrated in Figure 3B, control animals showed a significantly higher frequency of interactions as indicated by a significant effect of diet $(\mathrm{F}(1,20)=40.62, \mathrm{P}<0.001)$. ANOVA also indicated a significant increase in the frequency of interactions throughout the lactation period as shown by a significant effect of days $(\mathrm{F}(5,100)=134.03, \mathrm{P}<0.001)$. However, a higher increase in the frequency of mother-pup interaction in control animals as compared with malnourished animals throughout the lactation period showed a significant effect of diet by day interaction $(\mathrm{F}(5,100)=15.42, \mathrm{P}<0.001)$. A post-hoc analysis showed a lower mother-pup interaction on days 15,18 and 21 of lactation $(\mathrm{P}<0.05)$ in malnourished animals as compared to control animals. No effects of stimulation, diet by stimulation interaction, day

Figure 3 - Frequency of the separated litter (A) and frequency (B) and duration (C) of mother-pup interactions on each day of the lactation period. Each bar represents the mean \pm SEM during the night period $(6$ p.m. to 6 a.m.). $\mathrm{C}=\mathrm{CN}+\mathrm{CS}(\mathrm{N}=12$ litters); $\mathrm{M}=\mathrm{MN}+\mathrm{MS}(\mathrm{N}=12$ litters); $\mathrm{N}=\mathrm{CN}+\mathrm{MN}(\mathrm{N}=12$ litters); $\mathrm{S}=\mathrm{CS}+\mathrm{MS}(\mathrm{N}=12$ litters). $* \mathrm{P}<0.05$ compared to malnourished animals.

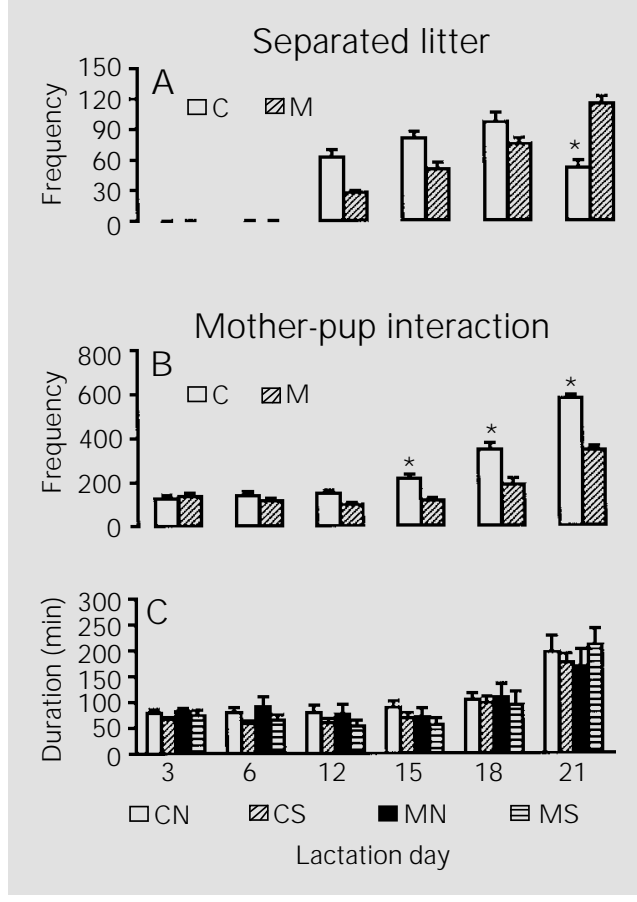

by stimulation interaction or diet by day by stimulation interaction were observed.

Regarding the duration of mother-pup interactions, ANOVA indicated only a significant effect of days $(F(5,100)=30.50$, $\mathrm{P}<0.001$ ), showing an increase in the interactions throughout the lactation period for both nutritional groups (Figure 3C). No other variables studied affected the duration of mother-pup interactions.

\section{Discussion}

Protein malnutrition led to a significant decrease in the body weight of mothers and pups throughout the lactation period as previously described by our laboratory $(5,13)$ and others (14), demonstrating the effectiveness of this malnutrition procedure. Tactile stimulation during the lactation period did not change pup body weight and did not interact with diet or days, indicating that this kind of stimulation was not sufficient to reduce the deficits produced by early protein malnutrition. The statistically significant interaction between tactile stimulation and days on dam body weight as the result of a lower weight loss in the group of mothers caring for non-stimulated pups cannot be easily explained. However, it is possible that the stimulation procedure interferes with the behaviors of mothers and pups in two different ways that could explain this difference. First, stimulated pups could be more active demanding more intensive care from their mothers and consequently expending more energy. Second, non-stimulated litters were not disturbed every day during the lactation period allowing the mothers to save more energy than stimulated mothers, since stimulated mothers were observed reconstructing the nest and carrying the pups after each stimulation procedure.

Although the lower frequency of suckling in malnourished animals may indicate a lower amount of nursing from the malnourished dams, this was not the case since mal- 
nourished dams spent significantly more time feeding their pups. This result suggests that malnourished mothers engage less frequently in suckling behavior, but once this occurs the pups remain suckling longer than control pups. One possible behavioral explanation is based on data clearly showing a decrease in total milk volume in malnourished mothers (15). This reduced amount of milk induces the malnourished pups to suckle in order to produce more milk, since mechanical stimulation of the mammary gland can induce milk ejection (16). The procedure of higher frequency of photos (4-s intervals) made it possible to show that although a lower frequency of suckling was observed in malnourished animals it was not indicative of a lower amount of nursing from the malnourished dams. The procedure of a lower frequency of photos was not sensitive enough to show that once the malnourished pups engage in suckling behavior they suckle longer than control pups.

The shorter suckling episodes in control litters could also be explained, at least in part, by maternal and litter response to the changes in temperature or maintenance of heating. There is evidence indicating that the duration of maternal nesting behavior is limited by the heat generated by mother-pup contact (17). Thus, once the temperature increases during the nursing behavior, the dam leaves the nest in order to lose heat, frequently assuming a resting position (lying on the side without contact with the pups). Since both the mother and pups in the malnourished group showed lower body weight as the result of protein deficiency, with a consequent lower amount of fat and less hair in the malnourished pups, this deficiency may alter the way the temperature rises during nursing behavior. Thus, the longer suckling episodes in malnourished litters may not be producing as much heat in the body of malnourished mothers as in control mothers, consequently leading to both longer suckling episodes and a reduced necessity for them to be out of the nest in the resting position to lose heat. As stated by Fleischer and Turkewitz (18), other factors such as dam energy may also explain the changes produced by malnutrition. The authors pointed out that "nursing tends to be increased because malnourished pups generate less heat and possibly also because the malnourished female herself produces less heat and has less energy with which to leave the litter" (18, pp. 47).

The lower frequency of resting position and separated litters in malnourished animals may also represent a higher dependence of malnourished pups on their mother. These results are in agreement with data in the literature $(8,10)$. These behavioral alterations may be a consequence of changes in the thermoregulatory process in malnourished animals, especially during the first days of the lactation period $(17,19,20)$. As mentioned above, some authors $(17,19)$ showed a lower temperature in malnourished pups, allowing the mother to stay in the nest more than the control mothers. Other factors affecting maternal behavior may be related to pup development since malnutrition produces retardation in neuromotor development (21). In addition, malnourished pups have been shown to present a higher frequency of ultrasonic calling, a factor that possibly determines an extension of the time the malnourished mothers spend with their pups (22). It is also important to interpret the lower frequency of separated litters as being due to the fact that malnourished pups use this as a way of saving energy, since locomotion or even loss of heat due to the separation from the mother and/or other pups results in energy expenditure.

The significant effect of days, as well as diet by day interaction on frequencies of suckling, resting position and separated litters also indicate not only that these behaviors are influenced by the course of lactation, but that a protein-deficient diet alters this course. 
The higher frequency of active interaction between mother and pups in the control group is in agreement with data reported by De Oliveira (10). Schamberg and Field (23) showed better development in stimulated animals and also increases in protein synthesis, growth hormones and some enzymes. The greater increase in the duration of motherpup interactions in the control group suggests that a good protein diet leads to better development. Control pups became more active and independent of their mother earlier during lactation, increasing the opportunity for social contacts initiated by the pups and thus increasing mother-pup interactions.

The increase in the time spent by the dams of all experimental conditions in the feeding tunnel throughout the lactation period could be a result of an increase in the independence of the pups, allowing the mothers more time to spend in other behaviors, including the feeding behavior.

The absence of significant effects of tactile stimulation and diet by tactile stimulation interaction on the behavioral categories analyzed indicates that this kind of stimulation did not affect these behaviors and that stimulation did not reduce changes produced by early protein malnutrition. The only changes produced by tactile stimulation were the higher frequencies of suckling and resting position. The stimulated animals slowly increased the frequency of suckling throughout lactation and showed higher frequencies of resting position at the beginning of the lactation period when compared to non-stimulated animals. These data, when compared to those reported by Levitsky and Barnes (7), may suggest that a more intense stimulation process and environmental enrichment would be necessary to produce recovery from behavioral changes induced by early protein malnutrition.

Our data showing longer sucking duration, lower resting position and less frequency of separated litter in the malnourished group may be interpreted as an increase in behavioral categories involved in the control of food intake and a decrease in other behaviors involving interactions with the environment, as described by Levitsky and Barnes (7).

\section{Acknowledgments}

The authors thank Dalmo C.P. Nicola for technical assistance.

\section{References}

1. Denenberg VH (1969). The effects of early experience. In: Hafez ESE (Editor), The Behavior of Domestic Animals. Bailliere, Trindall and Cassell, London, 95-130.

2. Morgane PJ , Austin-Lafrance RJ , Brozino J D, Tonkiss J, Díaz-Cintra S, Cintra L, Kemper T \& Galler J R (1993). Prenatal malnutrition and development of the brain. Neuroscience and Biobehavioral Reviews, 17: 91-128.

3. Levitsky DA \& Strupp BJ (1995). Malnutrition and the brain: Changing concepts, changing concerns. J ournal of Nutrition, 125: 2212S-2220S.

4. Renner J M \& Rosenzweig MR (1987). Enriched and Impoverished Environments: Effects on Brain and Behavior. SpringerVerlag, New York.

5. Santucci LB, Daud M M, Almeida SS \& De
Oliveira LM (1994). Effects of early protein malnutrition and environmental stimulation upon the reactivity to diazepam in two animal models of anxiety. Pharmacology, Biochemistry and Behavior, 49: 393398.

6. Barnes RH (1976). Dual role of environmental deprivation and malnutrition in retarding intellectual development. American J ournal of Clinical Nutrition, 29: 912917.

7. Levitsky DA \& Barnes RH (1972). Nutritional and environmental interactions in behavioral development of the rat: longterm effects. Science, 176: 68-71.

8. Massaro TF, Levitsky DA \& Barnes RH (1974). Protein malnutrition in the rat: its effects on maternal behavior and pup development. Developmental Psychobiol- ogy, 7: 551-561.

9. Levitsky DA, Massaro TF \& Bames RH (1975). Maternal malnutrition and the neonatal environment. Federation Proceedings, 34: 1583-1586.

10. De Oliveira LM (1985). Malnutrition and environment: interaction effects upon animal behavior. Revista Chilena de Nutrición, 13: 99-108.

11. Chaves AC \& Martinez C (1979). Nutrición y Desarrollo Infantil. Interamericana, Mexico.

12. Brozek J (1984). Functional isolation in man. In: Brozek J \& Schürch B (Editors), Malnutrition and Behavior: Critical Assessment of Key Issues. Nestlé Foundation, Lausanne, Switzerland, 424-427.

13. Rocinholi LF, Almeida SS \& De Oliveira LM (1997). Response threshold to aver- 
sive stimuli in stimulated early proteinmalnourished rats. Brazilian J ournal of Medical and Biological Research, 30: 407413.

14. Rocha J BT \& Mello CF (1994). Handling during suckling alters rat behavior but does not reverse the deleterious effects of undernutrition on naltrexone-induced inhibition of exploratory activity. International J ournal for Vitamin and Nutrition Research, 64: 152-156.

15. Crnic LS \& Chase P (1978). Model of infantile undernutrition in rats: effects of milk. J ournal of Nutrition, 108: 1755-1760.

16. Lau C \& Henning SJ (1984). Regulation of milk ingestion in the infant rat. Physiology and Behavior, 33: 809-815.

17. Leon M, Croskerry PG \& Smich GK (1978). Thermal control of mother-young contact in rats. Physiology and Behavior, 21: 793811.

18. Fleischer SF \& Turkewitz G (1984). The use of animals for understanding the effects of malnutrition on human behavior: Models vs. a comparative approach. In: Galler J R (Editor), Nutrition and Behavior. Plenum, New York, 37-61.

19. Culley WJ (1972). Body temperature of infant rats: effect of maternal diet. Nutritional Reports International, 6: 359-363.

20. Ader R \& Grota LJ (1970). Rhythmicity in the maternal behavior of Rattus norvegi- cus. Animal Behavior, 18: 144-150.

21. Smart J L \& Dobbing J (1971). Vulnerability of the developing brain. II. Effects of early nutritional deprivation on reflex ontogeny and development of behaviour in the rat. Brain Research, 28: 85-95.

22. Hennessy MB, Smotherman WP, Kolp L, Hunt L \& Levine S (1978). Stimuli from pups of adrenalectomized and malnourished female rats. Physiology and Behavior, 20: 509-514.

23. Schamberg SM \& Field TM (1987). Sensory deprivation stress and supplemental stimulation in the rat pup and preterm human neonate. Child Development, 58: 1431-1447. 